\title{
www.czasopisma.pan.pl \\ The Effect of Additive "B" on the Properties of Foundry Sands with Hydrated Sodium Silicate Made by Floster Technology
}

\author{
I. Izdebska-Szanda, J. Kamińska*, M. Angrecki, A. Palma, Z. Stefański \\ Foundry Research Institute, Department of Technology \\ Zakopiańska St. 73, 30-059 Crakow, Poland \\ * Contact for correspondence: E-mail: jadwiga.kaminska@iod.krakow.pl
}

Received 15.09.2016; accepted in revised form 07.02.2017

\begin{abstract}
The aim of the study was to determine the applicability of a new product added to water glass-containing foundry sands hardened with ethylene glycol diacetate. The new additive designated by the symbol "B" is a composition of aqueous solutions of modified polyalcohols, improving the sand knocking out properties. The scope of studies included testing various mechanical and technological properties of foundry sand mixtures, such as permeability, friability, life cycle of cores and knocking out properties.

In the technological studies, two types of water glass with different values of the silica modulus and density, designated as R145 and R150, were used. Moulding sands were prepared with the additive "B". For comparison, reference sands with water glass but without the additive "B" were also made. In Part I of the article, the results of studies of the effect of additive "B" on the properties of foundry sands with water glass hardened by $\mathrm{CO}_{2}$ blowing were discussed.
\end{abstract}

Keywords: Moulding sand, Water glass, Floster S technology, Additive to moulding sand

\section{Introduction}

Water glass as a binder has been used in the foundry industry for many years [1]. Hydrated sodium silicate is one of the most popular and commonly applied inorganic binders [2-8].

With the ever more stringent requirements of environmental protection, increasingly important are becoming these technologies that, apart from the required technological parameters, are also the least harmful to the environment. Among the moulding and core sands, the sands with water glass seem to be precisely this type of product $[9,10]$.

The primary reason for the promotion and use in the past, present and future of moulding sands with the silicate binder is a wide scope of their beneficial properties, mainly the absence of health risks for workers involved in the application of this process $[11,12]$.

However, the said technology, while offering a cheap and environmentally friendly method for the manufacture of foundry moulds and cores, has also some drawbacks, which include poor sand collapsibility and reclamability, mechanical in particular [13].

\section{Research programme}

The programme of own studies was based on the use of two types of water glass, i.e. R145 and R150 with the silica modulus and density amounting to $\mathrm{M}=2.5$ and $\rho=1.45 \div 1.48 \mathrm{~g} \cdot\left(\mathrm{cm}^{3}\right)^{-1}$, 
and $\mathrm{M}=2.0$ and $\rho=1.50 \div 1.53 \mathrm{~g} \cdot\left(\mathrm{cm}^{3}\right)^{-1}$, respectively. The hardener for water glass was ester (ethylene glycol diacetate) of the trade name Flodur 3, used in an amount of $10 \%$ relative to the binder content.

The test programme has involved the preparation of moulding sands with additive "B", which is a composition of aqueous solutions of modified polyalcohols. The reference moulding sand was sand with water glass but without the additive "B". All moulding sands were prepared in a ribbon-type laboratory mixer, model LMR-2. The base sand was first mixed with the hardener (Flodur 3) for 90 seconds, and then water glass or a composition of water glass and additive "B" was introduced, and the whole was again mixed for 90 seconds.

The ready moulding sands were evaluated for their technological properties, including the determination of permeability $\mathrm{P}$, friability $\mathrm{S}$, compressive strength $\mathrm{R}_{\mathrm{c}}$ and bending strength $\mathrm{R}_{\mathrm{g}}$. The compressive strength and bending strength were measured after the moulding sand maturing time of 3 and 24 hours. Other technological properties were determined after the 24 hour maturing time.

\section{Test results}

Part of the research programme assumed making reference moulding sands containing water glass R 145 and R150 hardened with ethylene glycol diacetate in Floster technology and also moulding sands with different amounts of additive "B" introduced to water glass R145 and R150. Mechanical properties were tested on the sand samples after the maturing time of 3 and 24 hours. Other technological properties were measured on the samples after the 24 hour maturing time.

The composition of the tested sand mixtures was as follows:

Silica sand - 100,0 parts by weight

Sodium water glass R145 - 2,5 parts by weight and R150

Flodur 3

Additive „B”

$-0,25$ parts by weight

- 0,$10 ; 0,15$ and 0,20 parts by weight.

\subsection{Permeability}

Figure 1 shows the impact of additive "B" on the moulding sand permeability. In both cases, i.e. in the sands with water glass R145 and R150 and the content of binder at a level of 2.5 parts by weight, the increasing amount of additive "B" introduced to the moulding sand has caused a slight decrease of the permeability.

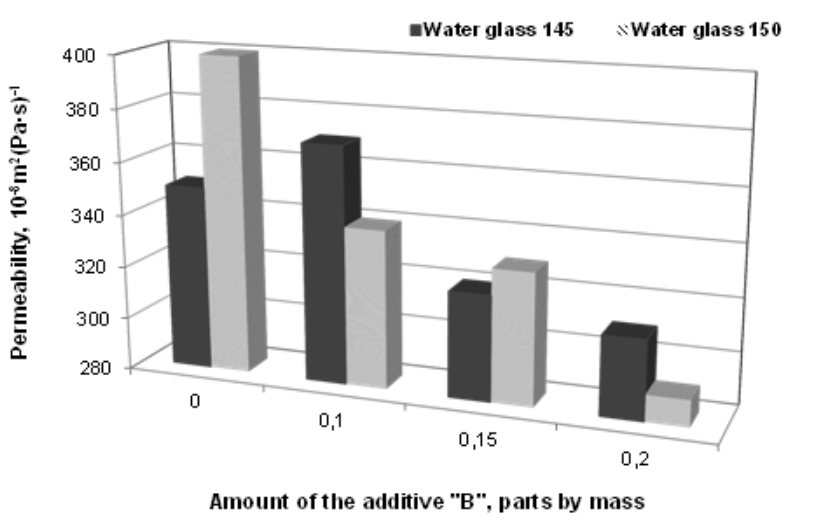

Fig. 1. The effect of additive "B" on sand permeability

\subsection{Friability}

Friability was determined according to BN-77/4024-02 in an LS apparatus measuring the relative weight loss in a sample rolled for 5 minutes on a pair of $50 \mathrm{~mm}$ dia. steel rollers rotating at a speed of $750 \mathrm{rpm}$ and heated with radiant lamp.

Figure 2 compares changes in the friability of moulding sands with water glass R145 and R150. In the sands with water glass $\mathrm{R} 145$, the additive "B" introduced to the sand has considerably increased the core friability. In the sands with water glass R150, the impact of this additive was much less pronounced. The lower is the friability, the more realistic are the prospects for making cores that will be able to withstand the abrasive and crushing effect.

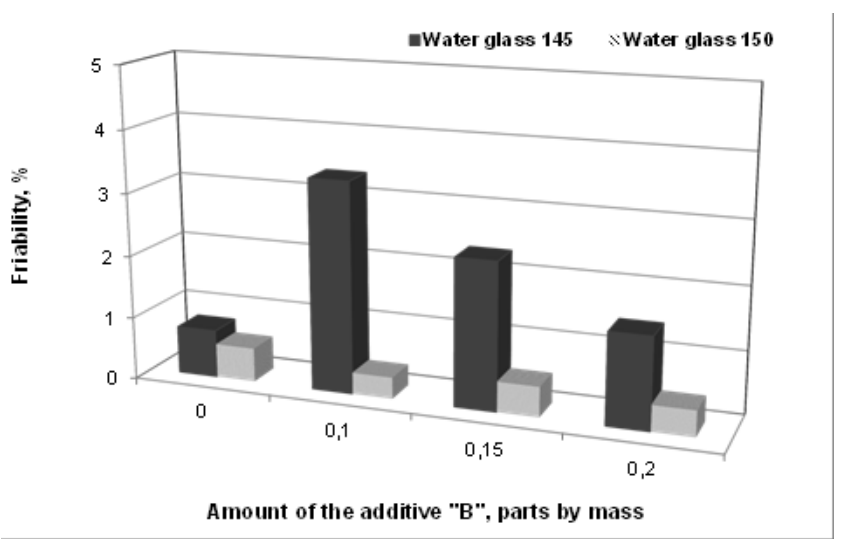

Fig. 2. The effect of additive " $\mathrm{B}$ " on sand friability

\subsection{Compressive strength}

Measurements of both the shear and bending strengths were performed in an LRU-2 type apparatus in accordance with the PN-83/H-11073 standard.

Figures 3 - 4 show the values of compressive strength measured as a function of the content of additive "B". The nature of changes in the strength properties is similar in all the 
investigated sands. The obtained results enable drawing the conclusion that with the assumed constant composition of the sand (constant amount of binder and hardener), the highest values of the compressive strength are obtained with the additive "B" introduced in an amount of about 0.2 part by weight. In this case, the decrease in compressive strength relative to the reference sand is the smallest and amounts to about $10 \div 15 \%$.

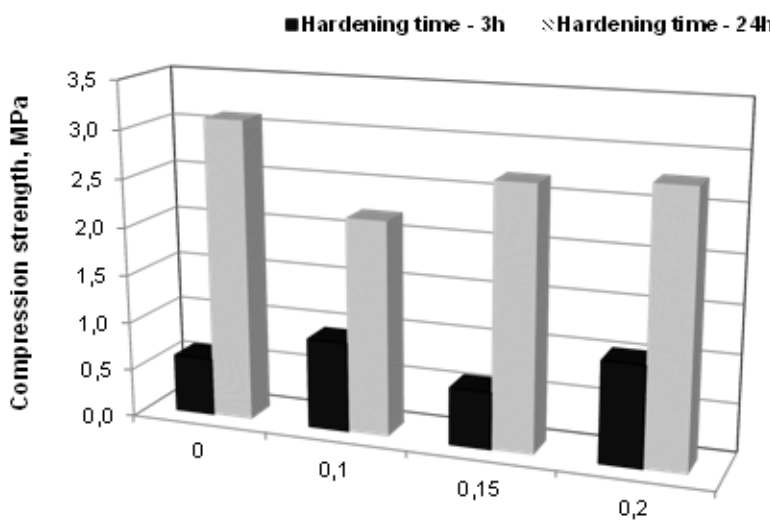

Amount of the additive "B", parts by mass

Fig. 3. The effect of additive "B" on the compressive strength of sand containing 2.5 parts by weight of water glass R145

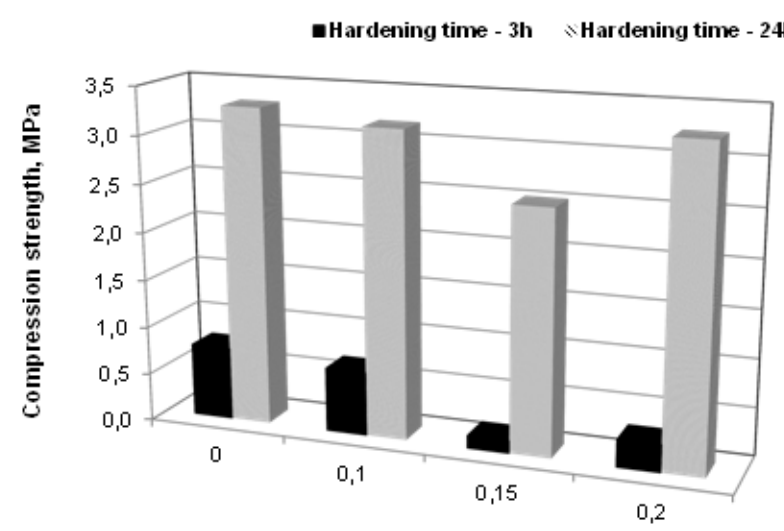

Amount of the additive "B", parts by mass

Fig. 4. The effect of additive "B" on the compressive strength of sand containing 2.5 parts by weight of water glass R 150

\subsection{Bending strength}

The results of the bending test carried out on the examined sands (Figs. 5 - 6) indicate that variations in the amount of additive "B" introduced to the sand composition have no major influence on the sand bending strength.

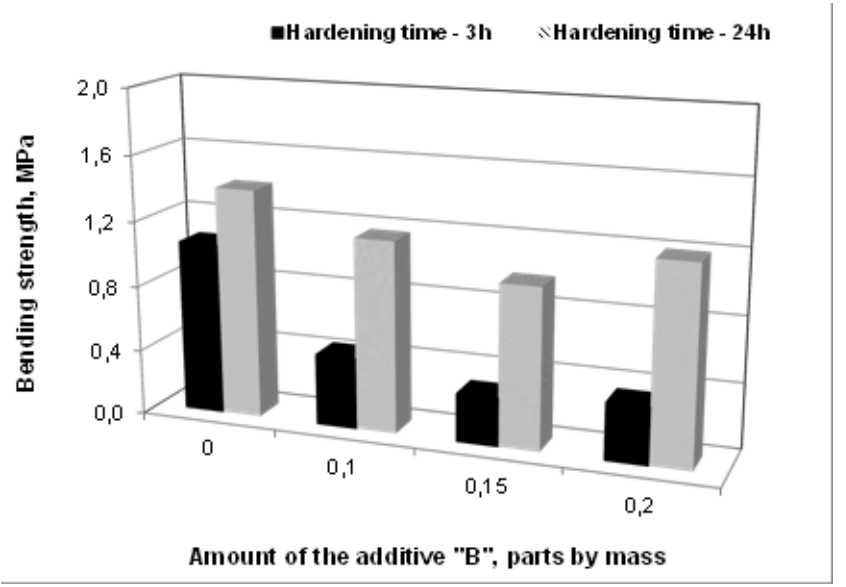

Fig. 5. The effect of additive "B" on the bending strength of sand containing 2.5 parts by weight of water glass R145

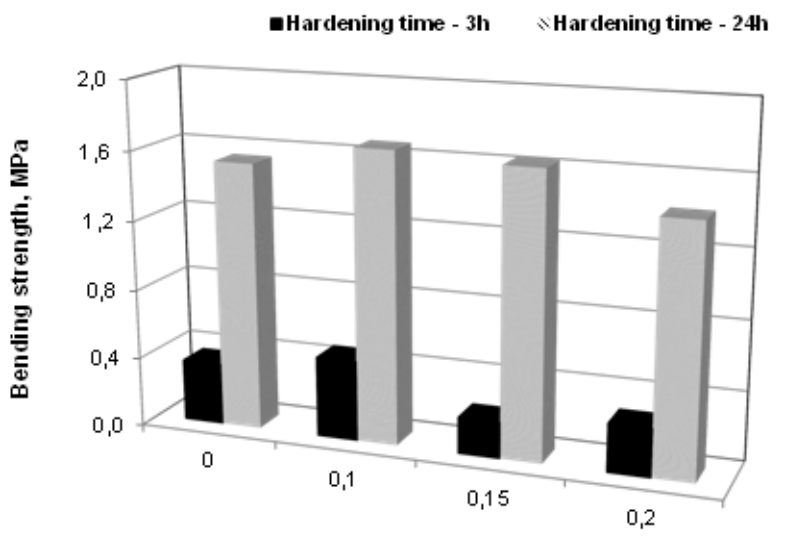

Amount of the additive "B", parts by mass

Fig. 6. The effect of additive "B" on the bending strength of sand containing 2.5 parts by weight of water glass R 150

\section{Summary}

The results of studies of the moulding sands prepared by Floster technology enabled drawing the following conclusions:

- The permeability of the reference sand is from 350 to $400 \cdot 10^{-8} \mathrm{~m}^{2} / \mathrm{Pa} \cdot \mathrm{s}$, depending on the type of water glass, while the permeability of the sand with additive "B" is from 290 to $370 \cdot 10^{-8} \mathrm{~m}^{2} / \mathrm{Pa} \cdot \mathrm{s}$ and depends on the type of water glass and the amount of additive "B" introduced to the sand.

- The friability of the reference sand is $0,55 \%$ regardless of the type of water glass, but with the introduction of additive "B" it assumes the values from 0,35 to $3,8 \%$, depending on the type of water glass and the amount of additive "B" introduced to the sand.

- The compressive strength of the reference sand after 24 hours of maturing is $3,3 \mathrm{MPa}$, while the compressive strength of the sand with the addition of additive "B" is from $2.2 \mathrm{MPa}$ to 3,3 
$\mathrm{MPa}$ and depends on the type of water glass and the amount of additive "B" introduced to the sand.

- $\quad$ The bending strength of the reference sand after 24 hours of maturing is 1,5 MPa, while the bending strength of the sand with the addition of additive " $\mathrm{B}$ " is from

- $\quad 1,0 \mathrm{MPa}$ to $1,7 \mathrm{MPa}$ and depends on the type of water glass and the amount of additive "B" introduced to the sand.

Studies carried out on the test moulding sands produced by Floster technology indicate that the best results are obtained with the content of additive " $\mathrm{B}$ " amounting to 0,1 part by weight.

\section{Acknowledgements}

This article was developed under the statutory project No. 5005/00 - "Upgrading the technology of moulding sands with inorganic binders to improve the economy and quality of castings, especially castings produced from the non-ferrous metal alloys" and Financial support of The National Centre for Research and Development LIDER/028/593/L-4/12/NCBR/2013.

\section{References}

[1] Zhu, C. (2007). Recent advance in waterglass sand technologies. China Foundry. 4(1), 13-17. DOI 10.1007/s41230-016-5117-8.

[2] Izdebska-Szanda, I. (2012). The economic and ecological aspects of using the modified water glass. TEKA. 12(2), 67-71.

[3] Fan, Z. \& Huang, N. et al. (2005). Dry reusing and wet reclaiming of used sodium silicate sand. China Foundry. 2(1), 38-43. DOI 10.1007/s41230-016-5117-8.
[4] Żółkiewicz, Z. \& Żółkiewicz, M. (2010). Characteristic properties of materials for evaporative patterns. Archives of Foundry Engineering. 10(spec.3), 289-292.

[5] Baliński, A. \& Wilkosz, B. (1999). The structure of hydrated sodium silicate (water glass) produced by various methods. Solidification of Metals and Alloy. 1(41), 206-212.

[6] Kamińska, J. \& Dańko, J. (2013). Granulation of after reclamation dusts from the mixed sand technology: water glass - resolit. Archives of Foundry Engineering. 12(2), 65-70.

[7] Stypuła, B., Kmita, A. \& Hajos, M. (2014). Morphology and structure of $\mathrm{ZnO}$ nanoparticles produced by electrochemical method. Materials Science. 20(1), 3-9. DOI:10.1179/0267 08304225022278 .

[8] Wang, J. \& Fan, Z. el at. (2007). An improved sodium silicate binder modified by ultra-fine powder materials. China Foundry. 4(1), 26-30. DOI 10.1007/s41230-0165117-8.

[9] Wang, J. \& Fan, Z. el at. (2009). Properties of sodium silicate bonded sand hardened by microwave heating. China Foundry. 6(3), 191-196. DOI 10.1007/s41230-016-5117-8.

[10] Smyksy, K., Kmita, A. \& et al. (2014). Cohesion and adhesion properties of modified water glass with colloidal solutions of ZnO. Metallurgy. 53(4), 459-462.

[11] Izdebska-Szanda, I. \& Baliński, A. (2011). New generation of ecological silicate binders. Procedia Engineering. 10, 887-893.

[12] Granat, K., Nowak, D. \& Stachowicz, M. (2010). The use of innovative methods of curing microwave manufacturing processes for steel castings for the engineering industry. Archiwum Technologii Maszyn i Automatyzacji. 30(1), 1927. (in Polish).

[13] Major-Gabryś, K., Dobosz, St.M. et al. (2012). The influence of Glassex additive on properties of microwave-hardened and self-hardened moulding sands with water glass. Archives of Foundry Engineering. 25(1), 130-134. 